\title{
Proyecto Histocarto: aplicación de SIGs (georreferenciación y geolocalización) para mejorar la recuperación de la documentación histórica gráfica
}

\author{
Histocarto project: Application of GIS tools \\ (georeferencing and geolocation) to improve the \\ retrieval of graphic historical documents
}

\author{
Jesús-Daniel Cascón-Katchadourian; Antonio-Gabriel López-Herrera; Antonio-Ángel \\ Ruiz-Rodríguez; Enrique Herrera-Viedma
}

Cómo citar este artículo:

Cascón-Katchadourian, Jesús-Daniel; López-Herrera, Antonio-Gabriel; Ruiz-Rodríguez, Antonio-Ángel; Herrera-Viedma, Enrique (2019). "Proyecto Histocarto: aplicación de SIGs (georreferenciación y geolocalización) para mejorar la recuperación de la documentación histórica gráfica". El profesional de la información, v. 28, n. 4, e280416.

https://doi.org/10.3145/epi.2019.jul.16

Artículo recibido el 28-03-2019 Aceptación definitiva: 24-05-2019

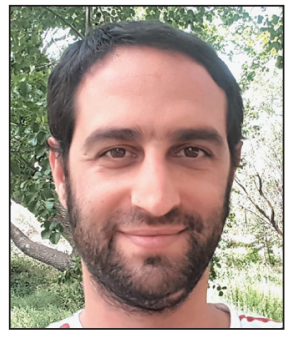

Jesús-Daniel Cascón-

Katchadourian $\square$

http://orcid.org/0000-0002-3388-7862

Universidad de Granada

Facultad de Comunicación y Documentación

Campus Universitario de Cartuja

Edificio Máximo. 18071 Granada, España

cascon@ugr.es

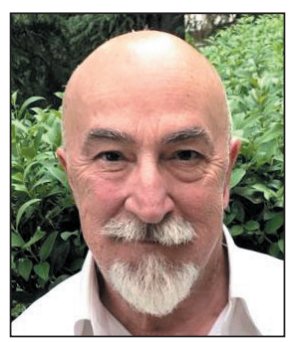

Antonio-Ángel Ruiz-Rodríguez http://orcid.org/0000-0002-3895-9546

Universidad de Granada

Facultad de Comunicación y Documentación

Campus Universitario de Cartuja

Edificio Máximo. 18071 Granada, España

aangel@ugr.es

\section{Resumen}

Se presenta el proyecto Histocarto, cuyo objetivo es la creación de un geoportal donde los potenciales usuarios puedan disfrutar, de forma fácil, cómoda e intuitiva, de parte del patrimonio histórico cartográfico y fotográfico de la ciudad de Granada, centrándose principalmente en lo referente a urbanismo y paisaje. La recuperación de este tipo de documentación hoy en día no es efectiva en otras webs institucionales, en perfiles de redes sociales o en webs personales. A través de la metodología adecuada que incluye: localización, selección, digitalización, descripción, georreferenciación (cartografía) y geolocalización (fotografía), teselación y publicación web, se ha obtenido como resultado un geoportal o visualizador cartográfico donde poder hacer búsquedas textuales tradicionales mejoradas con filtros, búsquedas geográficas más intuitivas, comparar el pasado y el presente entre los documentos, y poner en relación unos documentos con otros.

\section{Financiación}

Este trabajo ha sido financiado por la Universidad de Granada, ayuda al Contrato Puente. Proyecto TIN2016-75850-R: Sistemas inteligentes de toma de decisiones y consenso en ambiente difuso: Aplicaciones en e-salud y e-comercio. Proyecto 8 Medialab de la Universidad de Granada: Granada: viaje en el tiempo a través de su documentación histórica. 


\title{
Palabras clave
}

Cartografía antigua; Mapas; Fotografía antigua; Historia; Patrimonio fotográfico; Digitalización; Publicación web; Georreferenciación; Geolocalización; Geoportales; Visualizadores cartográficos; SIG; Sistemas de información geográfica; Recuperación de información; Histocarto.

\begin{abstract}
The Histocarto project aims to create a geoportal where potential users can enjoy in an easy, comfortable and intuitive way, part of the historical cartographic and photographic heritage of the city of Granada, focusing mainly on urbanism and landscape. The retrieval of this kind of documents nowadays is not effective in other institutional webs, in profiles of social networks or in personal web sites. Through the appropriate methodology that includes: location, selection, digitization, description, georeferencing (cartography) and geolocation (photography), tiling and web publication. As a result we have obtained a geoportal or cartographic visualizer where we can carry out traditional textual searches improved with filters, more intuitive geographic searches, past-present comparison of documents, and link documents.
\end{abstract}

\section{Keywords}

Old cartography; Maps; Old photography; History; Photographic heritage; Digitization; Web publishing; Georeferencing; Geolocation; Geoportals; Cartographic displays; GIS; Geographic information systems; Information retrieval; Histocarto.

\section{Introducción ${ }^{1}$}

En este trabajo se describe el proyecto Histocarto, un geoportal creado para lograr una mejor recuperación de la documentación histórica gráfica de la ciudad de Granada.

http://histocarto.ugr.es

En esta introducción se define brevemente, por un lado, el objeto de difusión del portal: la documentación histórica gráfica; y por otro, qué se entiende por georreferenciación y geolocalización; todo ello servirá para exponer un estado de la cuestión referente a ambas técnicas informáticas, que son de suma importancia en esta investigación.

Sobre el primer punto, la documentación histórica gráfica, cada una de estas tres palabras nos hace remontar a las definiciones ya examinadas y establecidas en multitud de trabajos. Para la definición de "documento" nos quedamos con la opinión de la especialista Rodríguez-Bravo $(2002)^{2}$, que ella distingue del concepto "fuente de información" dado que este último es más amplio que el de documentación: el documento es un mensaje emitido con intención comunicativa y potencialmente informativo para el receptor. Para que algo se pueda considerar documento tiene que haber una finalidad informativa primordial. En su defecto, la fuente de información sería cualquier ente u objeto del que alguien pueda sacar información, aunque no se haya concebido para ese fin.

Igualmente numerosa y sin acuerdo se muestra la bibliografía consultada sobre cómo categorizar los documentos, ni siquiera en denominar la categorización (Schellenberg, 1961; Guinchat; Blanquet; Menou, 1992; Cruz-Mundet, 2001; Rodríguez-Bravo, 2002). Nos decantamos por la opinión de Cruz Mundet y Schellenberg para denominar la categorización de los documentos; para ellos,

"la clase está determinada por el procedimiento empleado para transmitir la información", mientras que

"el tipo: es una característica que va más allá de lo meramente físico o externo... y deriva de la acción representada... Si se trata de legislar será una ley; si de informar, un informe...".

En esta investigación nos guiaremos por la opinión de Guinchat, Blanquet y Menou (1992) en lugar de otros autores (Cruz-Mundet, 2001; Rodríguez-Bravo, 2002), y trabajaremos con la clase de documentos iconográficos o gráficos, que son los que incluyen:

“imágenes, mapas, planos, gráficos, esquemas, carteles, cuadros, fotografías en papel, diapositivas".

En cuanto a los documentos históricos hay un consenso más o menos generalizado, con matices, sobre su significado. En el artículo de Cascón-Katchadourian, Ruiz-Rodríguez y Herrera-Viedma (2019) se hace todo un recorrido por lo que dicen las instituciones (España, 1995; 2003), legislación (España, 1969; 2002; 2011) y la bibliografía (Heredia-Herrera, 1991; Junta de Andalucía, 2000; Cruz-Mundet, 2001; Duplá-del-Moral, 2009). No nos detendremos más en ello. Sólo señalaremos que, como consecuencia de todas las normas aplicadas por los organismos oficiales a los distintos documentos históricos, en este proyecto web consideraremos como objetos de estudio los documentos gráficos previos a 1988, ya que toda documentación de más de 30 años que no ha sido previamente expurgada adquiere un valor histórico.

Sin embargo, debemos tener en cuenta que, en cuanto a la producción de la cartografía, los avances tecnológicos que llegan de la mano de la fotogrametría hacen que ésta se haga masiva durante la Segunda Guerra Mundial. Gestionar esta documentación con sólo nuestros medios es inalcanzable; por ello, en nuestra web no existen documentos cartográficos 
posteriores a 1950. En el caso de la fotografía, la situación es bastante diferente puesto que se hace inabarcable mucho antes. Como límite cronológico al objeto de estudio para la fotografía histórica nos hemos propuesto que ésta sea realizada en el siglo XIX y sólo mostraremos algunas fotografías interesantes posteriores a 1900, hasta 1910.

\subsection{Georreferenciación, geolocalización}

Como ya señalamos en el título del presente trabajo, las dos técnicas fundamentales que utilizamos en nuestro proyecto Histocarto son la georreferenciación y la geolocalización. Estas dos técnicas son el medio para hacer más accesible la información mediante búsquedas geográficas. Son geoprocesos para dotar de coordenadas geográficas a las fotografías y planos antiguos, lo cual permite que luego puedan ser buscados y visualizados en su lugar correspondiente.

Pasamos en primer lugar a definir estas dos técnicas, para exponer posteriormente el modo en que nos ayudan en nuestro trabajo, y en otros campos, y proceder a mostrar el estado de la cuestión de las mismas.

Para su definición, reproducimos lo que el sitio web del popular SIG (sistema de información geográfica) de la empresa ESRI (Environmental Systems Research Institute) precisa al respecto:

"Los datos ráster se obtienen, comúnmente, al escanear mapas o recopilar fotografías aéreas e imágenes de satélite. Los datasets de mapas escaneados, por lo general, no contienen información de referencia espacial (ya sea incorporada en el archivo o como un archivo separado). Con las fotografías aéreas y las imágenes de satélite, a veces la información de ubicación que se entrega con ellas no es adecuada y los datos no se alinean correctamente con otros datos que ya tiene. Además, para utilizar algunos datasets ráster junto con los otros datos espaciales, es posible que deba alinearlos o georreferenciarlos en un sistema de coordenadas de mapa. Un sistema de coordenadas de mapa se define mediante una proyección de mapa (un método por el cual la superficie curva de la tierra se representa en una superficie plana). Cuando realiza una georreferenciación de los datos de ráster, define su ubicación mediante coordenadas de mapa y asigna el sistema de coordenadas del marco de datos. La georreferenciación de datos de ráster permite visualizarlos, consultarlos y analizarlos con otros datos geográfi$\cos ^{\prime \prime}(\operatorname{ArCGIS}, 2016)$.

La georreferenciación consiste, pues, en identificar un lugar que sepamos que comparten con seguridad tanto la cartografía sin georreferenciar como la cartografía georreferenciada; técnicamente le estamos diciendo al sistema de información geográfica (SIG) que ambos puntos están en las mismas coordenadas. Si aplicamos lo dicho a la cartografía antigua, deberemos buscar lugares que se hayan mantenido en el tiempo, como pueden ser accidentes geográficos, monumentos, o calles.
La georreferenciación consiste en identificar un lugar que se sabe que comparten con seguridad tanto la cartografía sin georreferenciar como la cartografía georreferenciada; técnicamente se dice al SIG que ambos puntos están en las mismas coordenadas

Cada vez que indicamos al software, de una manera u otra, cuáles son los puntos homólogos, estamos creando lo que se llama puntos de control; cuanto mayor número de puntos de control se creen, más precisa será la georreferenciación (ArcGIS, 2013; 2016).

La geolocalización determina la situación precisa que ocupa un determinado objeto en el espacio, con sus coordenadas de latitud, longitud y altura (Beltrán-López, 2015). La geolocalización está adquiriendo mucha importancia ya que, una vez que se ha situado un objeto en el mapa, se le han sacado un gran número de funcionalidades y de servicios diferentes, obteniéndose a partir de ese momento información en tiempo real en relación con su posición geográfica (Ortiz-Caña, 2016). Este autor señala también cómo las dos tecnologías, georreferenciación y geolocalización, tienen en un principio su aplicación en el campo de la geografía. Últimamente han alcanzado una gran popularidad con su aplicación en webs y redes sociales. Aplicaciones como TripAdvisor, Google Maps, etc., utilizan esas técnicas para dar información al usuario en función de su localización y señalar los servicios que se encuentran próximos a su situación.

Pero es en la documentación histórica donde nos interesa, lógicamente, señalar la gran utilidad que proporcionan esas técnicas. La georreferenciación es especialmente útil al aplicarla a los fondos cartográficos. Ayuda a convertir una imagen digitalizada de un mapa antiguo en una capa interactiva que podría ser utilizada en un SIG o mostrada a través de un navegador web o de una app móvil (MapTiler, 2019), incorporando así coordenadas geográficas a un elemento que no las tenía. Mediante la digitalización y la publicación web, la georreferenciación facilita el acceso del usuario a la información contenida en un mapa o plano. Además, a través de sensores de transparencia se pueden comparar el mapa antiguo y el moderno, lo cual facilita estudios de evolución histórica por parte de los urbanistas, historiadores y arquitectos. Remitimos aquí a los trabajos que inciden en la importancia de la georreferenciación como área de estudio en sí misma dentro del campo de la cartografía (Witmer et al., 2006; Hill, 2009; Long et al., 2016).

La geolocalización determina la situación precisa que ocupa un determinado objeto en el espacio, con sus coordenadas de latitud, longitud y altura 
Por lo que respecta a la geolocalización, se utiliza principalmente en el estudio de la fotografía histórica, con objeto de facilitar al usuario la búsqueda a través de mapa. La técnica consiste en:

- identificar el lugar que muestra la fotografía antigua o desde donde fue tomada;

- se toman las coordenadas exactas del lugar;

- se introducen esas coordenadas en un sistema informático que mostrará en un mapa actual un símbolo en esa zona exacta, puede ser una chincheta, icono o una imagen a baja resolución de la fotografía antigua;

- una vez el usuario pincha en una de ellas le aparece una breve descripción y un enlace a la fotografía a tamaño completo y a su descripción completa.

Como ya se ha señalado en el caso de la georreferenciación, también en el de la geolocalización se consigue todo su potencial cuando se le unen la digitalización y la publicación web; con ello se consigue poder situar geográficamente las fotografías antiguas que posee una institución, por ejemplo, así como cualquier otro tipo de pinturas, carteles históricos, dibujos, etc. Asimismo, permite mejorar los sistemas de búsqueda puesto que los usuarios suelen buscar por temática o lugar.
La georreferenciación es especialmente útil al aplicarla a los fondos cartográficos. Ayuda a convertir una imagen digitalizada de un mapa antiguo en una capa interactiva que podría ser utilizada en un SIG o mostrada a través de un navegador web o de una app móvil

Entre los logros más interesantes destaca la realización de estudios sobre la evolución de un lugar o una zona de la ciudad a través de sus fotografías.

Si estas técnicas las combinamos con otras tecnologías, como pueden ser los filtros de tiempo, épocas, tipo de técnica fotográfica o cartográfica u otros (Southall; Přidal, 2012), se obtienen resultados muy útiles para el usuario. Ello ha llevado a diversas instituciones culturales a llevar a cabo proyectos muy interesantes en este ámbito:

- aplicaciones que muestran, según la posición del usuario, dónde hay fotografía o cartografía antigua cerca;

- envío de alertas al móvil cuando se pasa cerca de una de éstas;

- sensores de transparencia que permiten comparar el contexto de una fotografía antigua en nuestro móvil con la realidad actual del mismo, entre otras (Ayuntamiento de Barcelona, 2018; Timeline Trip, 2019).

Son también muy interesantes otras aplicaciones con funciones parecidas a las que nosotros presentamos, pero cada una con su particularidad. Destacamos el proyecto HISDI-MAD (CSIC, 2019), un geoportal de cartografía y demografía histórica para la ciudad de Madrid, cuyo fin último es la vinculación de la cartografía histórica georreferenciada con el Registro Longitudinal de Población Histórico de la Ciudad de Madrid.

También es interesante Barcelona Darrera Mirada (Ayuntamiento de Barcelona, 2019), un recurso digital que presenta cartografía histórica georreferenciada, pero desde la perspectiva de un documental multimedia, consiguiendo facilitar la consulta de los planos y proporcionando información a través de recursos multimedia y fotografías históricas.

Por lo que respecta al estado de la cuestión habría que destacar varios nombres, a modo de resumen del plasmado en la tesis doctoral de Cascón-Katchadourian (2018).

Petr Přidal, CEO de Klokantech, compañía especializada en publicación de mapas online, dedicada a mejorar la recuperación de información geográfica y aplicaciones para el sector cultural de código abierto (Klokan Technologies, 2019). Es creador de softwares como: Old maps online (Southall; Přidal, 2012), Georeferencer (Fleet; Kowal; Přidal, 2012), o MapRank (Oehrli et al., 2011).

David Rumsey, presidente de Cartography Associates y fundador de la David Rumsey Map Collection (Rumsey, 2019), autor de varios libros (Rumsey; Williams, 2002; Rumsey; Punt, 2005) y poseedor de una enorme colección de planos históricos digitalizados y en vías de georreferenciarse.

En España también hay expertos que han publicado artículos interesantes sobre georreferenciación de cartografía antigua, tanto propuestas metodológicas (Dávila-Martínez; Camacho-Arranz, 2012) como sobre georreferenciación colaborativa (Ramos; Roset, 2012), así como una útil monografía con una introducción a los SIG en humanidades y en ciencias sociales, muy valiosos para los estudiosos de estas ciencias (Del-Bosque-González et al., 2012).

Sobre la aplicación de la georreferenciación de cartografía antigua en temas puntuales, son muchos los posibles usos, desde cambios en el paisaje urbano (San-Antonio-Gómez; Velilla; Manzano-Agugliaro, 2014; Podobnikar, 2010), hasta estudios histórico-morfológicos sobre cambios en la línea de costa (Hapke; Reid, 2007), los deltas (Acuña-Piedra; Quesada-Román, 2016) o incluso la creación de islas (Quesada-Román; Acuña-Piedra, 2017).

Sobre la geolocalización de fotografía antigua la bibliografía es muy escasa. En cuanto a artículos generales que tratan sobre la geolocalización de fotografía antigua y sus usos en las instituciones, hay tan sólo un artículo propio (Cascón-Katchadourian; Ruiz-Rodríguez; Alberich-Pascual, 2018), y bibliografía que analiza un ejemplo concreto, como es la red social de geolocalización de fotografía antigua: Historypin (Armstrong, 2012; Harkema; Nygren, 2012; Baggett; Gibbs, 2014). 


\section{Objetivos}

El proyecto Histocarto tiene como misión fundamental facilitar la recuperación de las imágenes gráficas o iconográficas digitales de contenido histórico de la ciudad de Granada. Para ello se basa en el medio de comunicación de nuestros días: la web e internet. Advertimos de entrada que el geoportal resultante que muestra esta documentación está ideado y diseñado para mostrar documentación histórica gráfica también de otras ciudades o países.
El proyecto Histocarto tiene como objetivo facilitar la recuperación de las imágenes gráficas o iconográficas digitales de contenido histórico de la ciudad de Granada http://histocarto.ugr.es

Para conseguir ese objetivo general se ha fijado una serie de objetivos específicos que podríamos agrupar en dos grupos:

A) Conocimientos y habilidades que se han de adquirir:

- Averiguar qué instituciones culturales o coleccionistas privados tienen fondos de nuestro interés.

- Conocer qué instituciones, proyectos e investigadores se dedican a la temática relativa a esta investigación y qué herramientas usan en sus investigaciones. Conocer las normas de digitalización, descripción, estándares y tipos de metadatos que conciernen a estos documentos.

- Aprender y dominar las técnicas informáticas relacionadas con este proyecto: digitalización, compresión, formatos de archivo, teselación, publicación web y diseño y uso de entidades, atributos y relaciones en una base de datos.

- Controlar las técnicas informáticas que permiten al usuario mejorar la recuperación de la información a través de otro tipo de búsquedas distintas a las tradicionales, como son las búsquedas geográficas, es decir, la georreferenciación y la geolocalización.

B) Tareas o procesos que se han de ejecutar:

- Búsqueda de fondos, selección de las muestras dentro de la población de planos y fotografías históricas. Catalogar y describir dichas muestras.

- Ejecutar los procesos informáticos necesarios para subir la documentación a la web con calidad y rapidez: digitalización de la cartografía y descarga de las digitalizaciones de fotografía histórica disponibles en las instituciones; unión de las imágenes digitalizadas en los planos de grandes dimensiones; recorte de las digitalizaciones; conversión y compresión al formato adecuado para la web; teselación en los documentos muy pesados.

- Implementar los procesos informáticos necesarios para permitir la búsqueda geográfica, tanto de la cartografía como de la fotografía. Implementar el formulario para la subida a la web de la documentación para que puedan ser encontrados a través del motor de búsqueda textual y el geográfico.

- Realizar las tareas necesarias para ofrecer a los usuarios herramientas que permitan comparar los documentos históricos con la actualidad. Para el caso de la cartografía, georreferenciar los planos y subirlos a la web, mostrando el plano antiguo y moderno, uno incrustado en el otro, con un sensor de transparencia que permitirá visualizar mejor los cambios. En el caso de la fotografía histórica, realizar fotografías de la actualidad semejantes a las antiguas, subir ambos documentos a la web y ofrecerlas en paralelo en una página web.

\section{Metodología}

En primer lugar se ha realizado un vaciado y revisión de las publicaciones y bibliografía sobre:

- El objeto de estudio de esta investigación, en concreto sobre ubicación de esta documentación en las instituciones, autores de la misma y los coleccionistas de fotografía histórica.

- Experiencias similares a la nuestra, incluyendo aportaciones del ámbito archivístico, bibliotecario, de las cartotecas e institutos geográficos que hayan georreferenciado y geolocalizado su documentación histórica, que permitan su búsqueda geográfica y que ofrezcan soluciones atractivas para comparar el pasado y el presente.

- Normativas y recomendaciones vigentes sobre digitalización: transporte, manipulación, preservación, conservación, captura de la imagen, resolución y control de calidad, formatos y soporte de las copias, almacenamiento, metadatos técnicos, etc.

- Descripción de la documentación cartográfica y fotográfica antigua: metadatos descriptivos, normativas y estándares aplicables en las instituciones que poseen esta documentación.

- Los SIG en lo que se refiere a la georreferenciación de cartografía: formas de visualización de la cartografía durante el proceso, uso del protocolo WMTS (web map tile service) como cartografía de referencia, remuestreo, programas de referencia y un largo etc.

- La teselación y su utilidad a la hora de visualizar rápidamente documentos pesados en internet; compresiones, en qué consisten, y las más utilizadas; la publicación web de documentación histórica, además de experiencias de repositorios con documentación histórica. 
En segundo lugar, y con el bagaje intelectual anterior, se diseñaron las muestras de documentación histórica sobre las que se realizó todo el procesamiento de la información. Para la elección de las mismas se han tenido en cuenta diversos límites.

- Para la cartografía hemos escogido la colección de cartografía del Archivo Histórico Municipal de Granada (AHMG), por su riqueza e importancia. A través de un proyecto concedido por el CEI BioTic de la Universidad de Granada, se digitalizó una tercera parte de dicha colección. Una muestra de 40 planos se ha georreferenciado y subido a la web. El proyecto que sustenta esta web, del Medialab de la Universidad de Granada, sigue activo en estos momentos por lo que las muestras de cartografía y fotografía irán creciendo paulatinamente.

- En lo concerniente a la fotografía, se ha buscado, dentro de los límites temporales ya detallados (siglo XIX), una muestra diversa desde el punto de vista geográfico, de modo que haya fotos de distintos sitios de la ciudad y no muchos de un mismo lugar. Este proyecto ha tenido en cuenta, además de la variedad geográfica, el interés de las fotografías para el proyecto, así como que se pueda realizar una foto actual para comparar.

En tercer lugar, sobre las muestras de la documentación se realizó una serie de procesos para poder mostrarlos en el sitio web:

1. Descripción de la muestra de cartografía y fotografía. No se han hecho las descripciones según un formato normalizado como puede ser ISAD (G) o ISBD, puesto que estas normas no están adaptadas a los problemas que estos documentos presentan a la hora de describirlos, y debido a que al usuario medio estas cuestiones no le interesan (García-Ruipérez, 2010). En el caso de los campos como la fecha o la descripción física, sí que siguen las reglas de puntuación ISBD. Además, siempre que ha sido posible, se ha enlazado al registro descriptivo en la institución propietaria que, por lo general, ha seguido alguna de estas normas.

Para las descripciones se han usado los instrumentos de descripción de las instituciones propietarias, y se han mejorado con nuestros conocimientos y con la bibliografía especializada.

2. Digitalización, compresión y formatos de archivo. Los conocimientos fueron adquiridos durante un proyecto CEI BioTic donde se digitalizó una parte de la colección de cartografía histórica del $A H M G$. Acompañados por un técnico del $A H M G$, aprendimos a digitalizar la muestra, así como a comprimir y formatear los archivos conforme a las normas y guías de digitalización. En este caso se siguieron las Recomendaciones técnicas para la digitalización de documentos (Junta de Andalucía, 2010). La elección de estas recomendaciones fue decisión de la dirección del $A H M G$.

La muestra de cartografía se digitalizó con un escáner Bookeye 3 (Image Access, 2019). Se trata de un escáner cenital cuya área máxima de escaneo es de $900 \mathrm{x}$ $630 \mathrm{~mm}$, por lo que caben mapas mayores que Din A1. Está configurado para exportar las digitalizaciones en formato tiff a una resolución de 300 pixels por pulgada. A este output se le recortan los bordes indeseables producto del escaneado y, posteriormente, con el software Adobe Photoshop se convierten al formato jpeg en calidad 8 (de 12 posibles), es decir calidad alta.

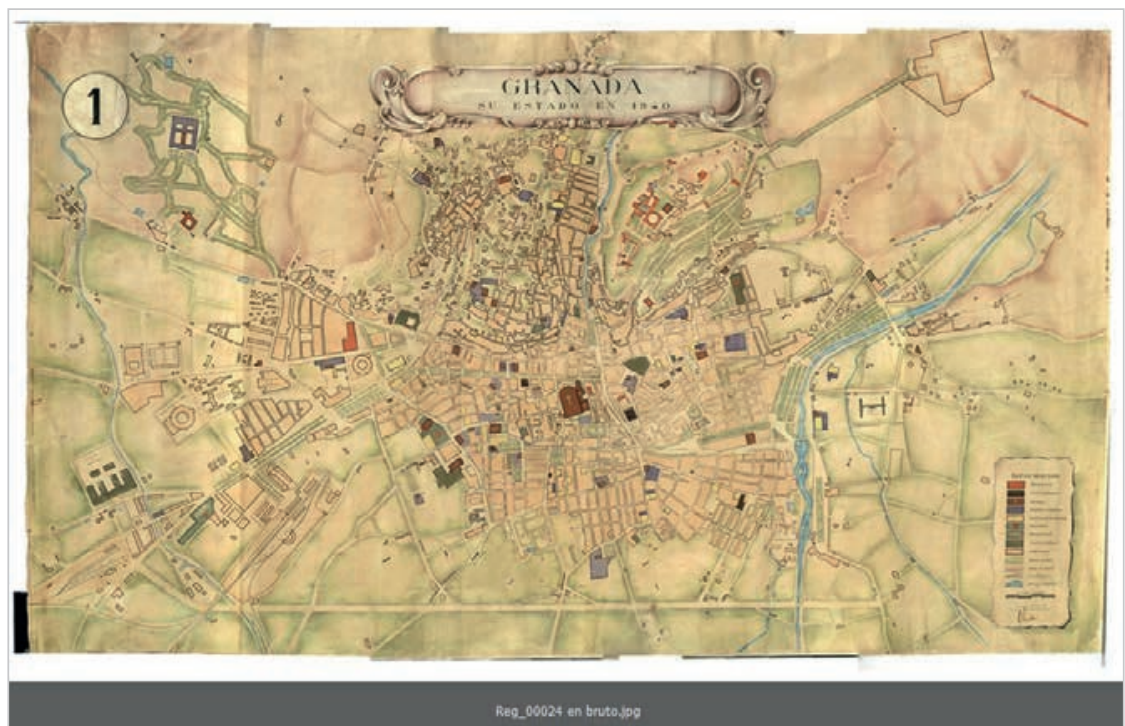

Figura 1. Registro 00024 con las 18 partes unidas a través de la función Photomerge de Photoshop. Obsérvense los bordes.

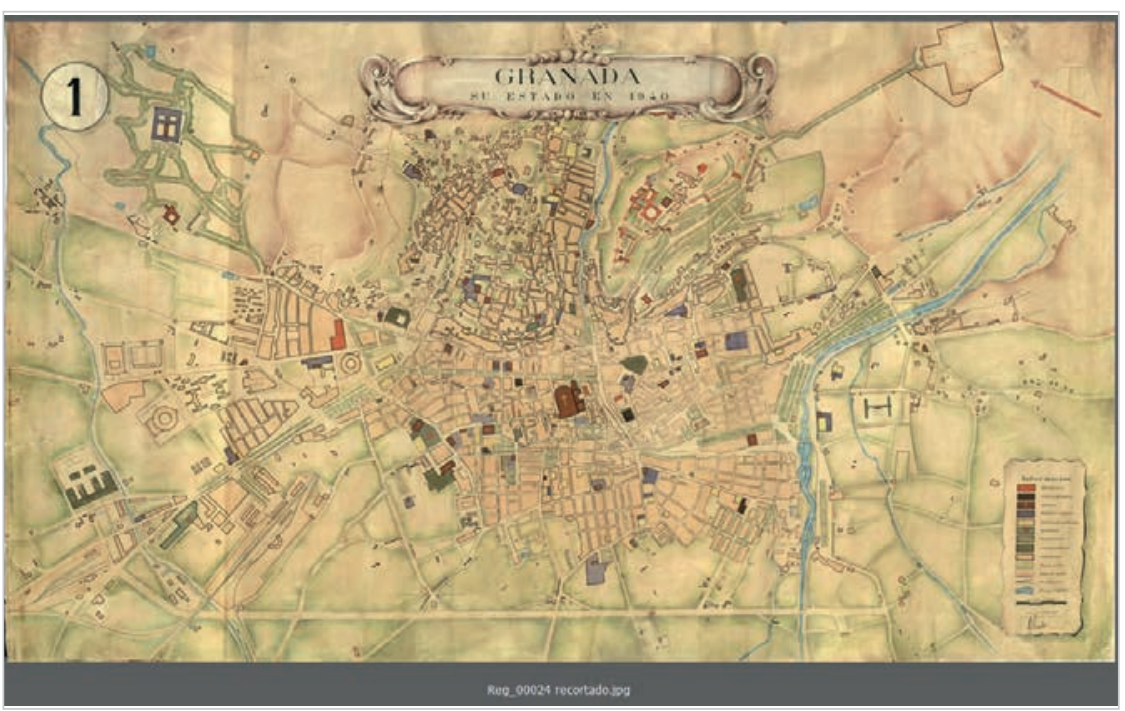

Figura 2. Registro 00024 con bordes eliminados 
Conforme a la legislación citada, los planos mayores de A1 se escanearon por cuadrícula y luego se unieron digitalmente mediante Photoshop con la función Photomerge (Adobe, 2018) el cual generaba una panorámica en tiff que ocupaba varios gigabytes con una resolución máxima; esa es la copia máster de almacenamiento (figura 1). Sobre ella se realiza el mismo proceso explicado anteriormente, se recortan los bordes (figura 2) y el resultado se convierte al formato jpeg de calidad alta.

3. Teselación. Un procedimiento muy útil para tratar imágenes tan extensas y complejas es lo que se denomina teselación de las imágenes (parcelación en figuras geométricas regulares, ver p. ej., figura 9). El proceso técnico está muy bien explicado en el artículo de Masó, Julià y Pons (2008). La teselación en la cartografía se realiza con el programa MapTiler con posterioridad a la georreferenciación, utilizando la función folder. El manejo del programa y cómo se realiza la teselación se puede consultar en un artículo de Cascón-Katchadourian y Ruiz-Rodríguez (2016). La teselación permite que el usuario pueda visualizar más rápidamente este tipo de documentos; a cambio, el plano resultante ocupa un mayor espacio en el servidor.

En cuanto a la fotografía, no se ha realizado digitalización. Se han ido seleccionando las fotografías de varias instituciones que poseen fotografía histórica digitalizada: Archivo Histórico Municipal de Granada, Archivo del Patronato de la Alhambra y el Generalife, Biblioteca Nacional, Colección particular Jiménez Yanguas, y Museo Casa de los Tiros. Los formatos de las fotografías antiguas digitalizadas son los que nos dan las instituciones; los más comunes son jpeg y pdf.

4. Georreferenciación de cartografía y geolocalización de fotografía. Tras haber determinado en una investigación anterior cuáles son los requisitos que debe cumplir un software para georreferenciar cartografía histórica (Cascón-Katchadourian; Ruiz-Rodríguez; Quesada-Román, 2018), y tras haberlos aplicado para analizar diversos SIG que existen en el mercado en cuanto a su función de georreferenciar cartografía antigua (artículo en vías de publicación), sacamos como conclusión que el programa que realiza la georreferenciación, la teselación y el proceso para subir a una web de una forma más intuitiva, fácil y rápida es MapTiler (ver funcionamiento en Cascón-Katchadourian; Ruiz-Rodríguez, 2016) y es el que hemos utilizado, con la opción Standard tiles.

Las opciones elegidas dentro del programa para este proyecto fueron:

- sistema de coordenadas: WGS84 (World Geodetic System 1984), o EPSG 4326 (European Petroleum Survey Group);

- georreferenciación: 10 ó más puntos de control en cada plano;

- transformación del ráster o interpolación: Thin Plate Spline;

- remuestreo: bilinear;

- formato de las teselas: png optimizado;

- esquema de teselamiento: OpenGIS WMTS / OpenStreetMap / Google XYZ (top-left origin);

- randerizado: folder de MapTiler.

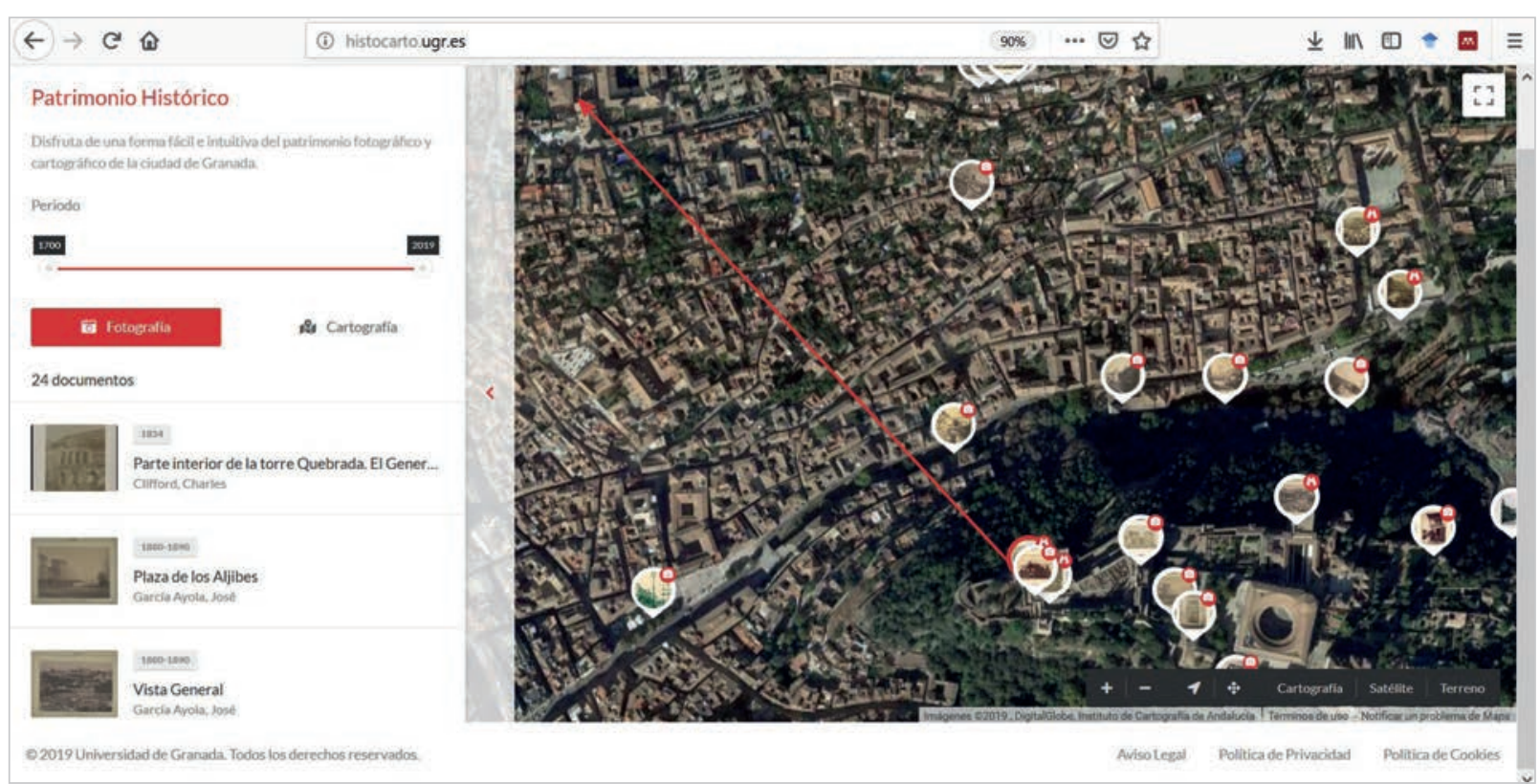

Figura 3. Ejemplo de flecha que sale al situar el ratón encima de un icono de panorámica 
El proceso de geolocalización de la fotografía antigua consiste en darle unas coordenadas. Para ello, hemos considerado que existen dos tipos de fotografías: las vistas o panorámicas, y las de monumentos en primer plano.

Las primeras se muestran en el visualizador geográfico con un icono de panorámica, que contiene dos pares de coordenadas en la base de datos, que están en el sistema de coordenadas WGS84 o EPSG 4326. El usuario observa el icono de panorámica en el lugar donde intuimos que estaba situado el fotógrafo, identificado con un primer par de coordenadas (longitud y latitud). Al situar el ratón encima de este icono sale una flecha; el segundo par de coordenadas guía la flecha hacia el sitio que muestra esas coordenadas, situadas en el centro de lo que se ve en la imagen o panorámica (figura 3).

El segundo caso es cuando el fotógrafo no ha captado una panorámica, sino que se ha situado delante de un monumento y le ha hecho una fotografía. En ese caso el icono es una imagen a baja resolución de pequeño tamaño. Estas fotografías sólo tienen un par de coordenadas en la base de datos, situadas en el monumento en cuestión.

5. Subida de documentos a la web y comparación pasado/presente. Los documentos se suben a una web diseñada por Everyware Technologies, una empresa spin off de la $U G R$, que ha realizado la arquitectura de la misma. A tal efecto, ha creado un formulario (figuras 4-5) donde se van dando de alta los registros de la documentación, adjuntando las imágenes digitalizadas, la descripción de cada una por campos, las coordenadas y las imágenes teseladas y georreferenciadas.

El formulario genera una ficha en la web con la descripción y la imagen digital asociada. Además, se incorpora al visualizador geográfico por mapa, lo cual permite que el usuario las visualice a través de un mapa de Google Maps.
Un panel de control permite gestionar la subida a la web de los documentos por separado: fotografías, cartografía, etiquetas, autores e instituciones

Un panel de control permite gestionar la subida a la web de los documentos por separado: fotografías, cartografía, etiquetas, autores e instituciones.

Con anterioridad a la creación de los registros de fotografía y cartografía, es necesario cumplimentar los campos autor, institución propietaria y etiquetas, que funcionan como entidades para poder relacionar unos documentos con otros.

Al registrar un documento se escoge el nombre del autor de un desplegable de autores rellenado previamente. Con eso se consigue normalizar los nombres de los autores y crear una relación entre los documentos que han escogido el mismo autor del desplegable. Lo mismo ocurre con el campo institución propietaria y el de las etiquetas.

En lo que respecta a la cartografía, MapTiler es el programa que facilita la subida a la web de los resultados. Además, permite la comparación del plano antiguo con el actual tipo Google Maps con la ayuda de un sensor de transparencia que quita y da opacidad al plano antiguo. Ello nos permite visualizar más fácilmente los cambios urbanos que se han producido con el paso de los años. En resumen, el programa da formato al plano antiguo incrustándolo encima del otro, lo "empaqueta" en carpetas y un index de tal forma que está listo para subirlo al servidor.

En cuanto a la fotografía histórica, para la comparación pasado/presente hemos realizado fotografías actuales lo más aproximadas posible a las antiguas. El formulario está diseñado para subir la fotografía antigua y la fotografía actual como adjuntos. Una vez haya seleccionado un registro en la web, el usuario puede ver la fotografía antigua en un lado de la pantalla y la fotografía moderna en el otro, lo que facilita su comparación.

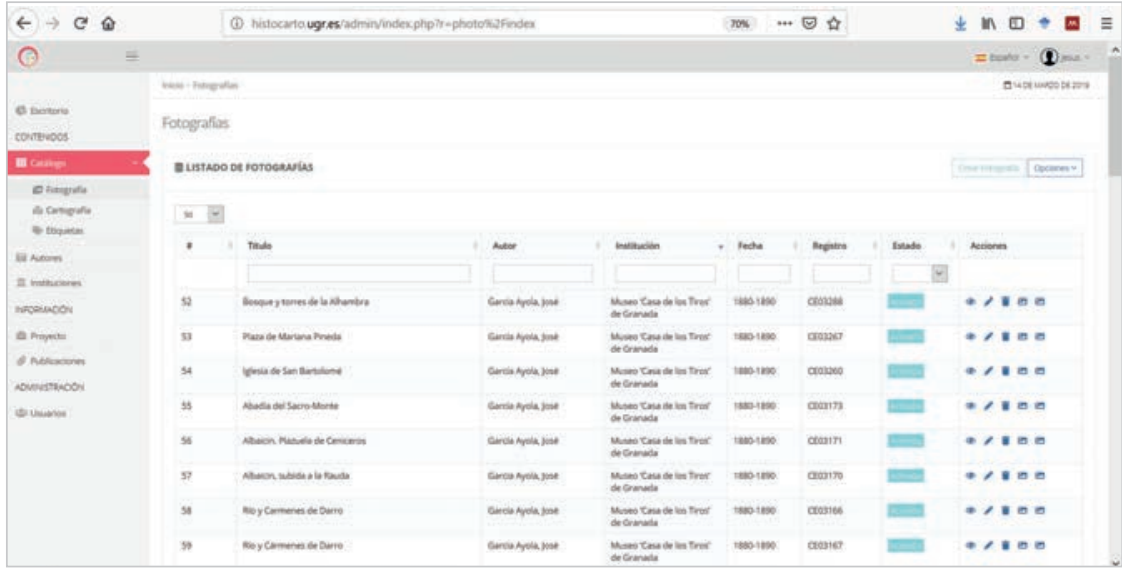

Figura 4. Formulario. Lista de documentos incluidos

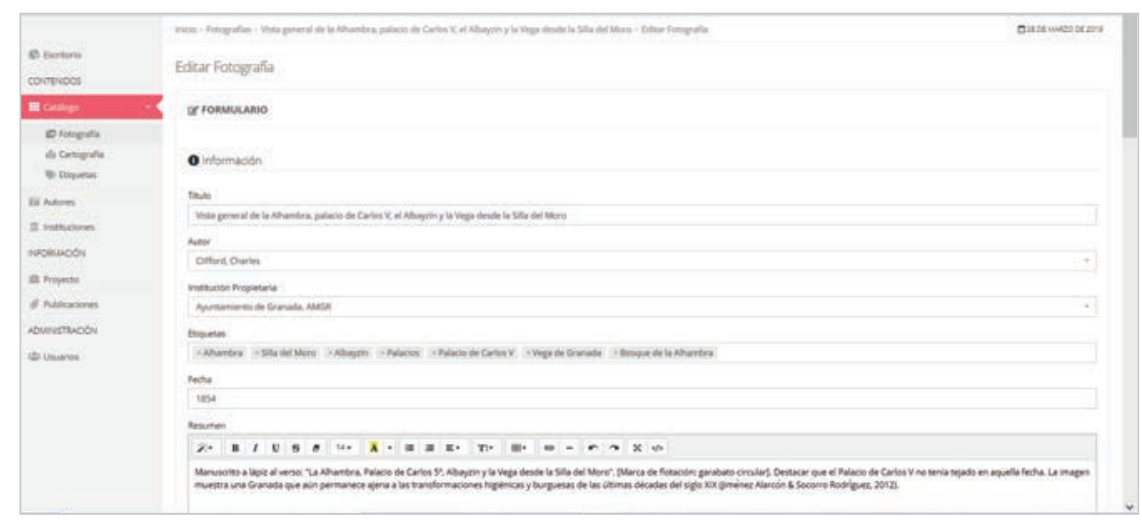

Figura 5. Formulario. Creación de un registro 


\section{Resultados}

Este proyecto ha obtenido los siguientes resultados:

1. La digitalización (cartografía) y la descarga de las imágenes (fotografías) ya digitalizadas por las instituciones, tras la selección realizada en función de nuestro interés. En la web del proyecto histocarto. ugr.es, en el apartado documentación, subapartado digitalizaciones (figura 6), se pueden ver todas las digitalizaciones que se realizaron de parte de la colección de cartografía del AHMG.

http://histocarto.ugres/digitalizaciones

Se digitalizaron 85 unidades documentales simples o compuestas; cada unidad corresponde a una obra específica; se les denomina registros. Concretamente, son 61 unidades simples más 24 unidades compuestas; en estas unidades compuestas se digitalizaron 295 planos. La mayoría de las unidades compuestas suelen ser planos de la ciudad que por su escala se realizan por partes (figura 7). Se digitalizó aproximadamente un tercio de la colección cartográfica del $A H M G$, que actuó además como una medida eficaz de protección del patrimonio histórico.

2. Teselación de los documentos. En la figura 8 vemos el resultado de la teselación de un plano. MapTiler genera una estructura de carpetas donde están las pequeñas tiles (baldosas) o teselas organizados según un número definido de zooms en carpetas numeradas. Cuanto mayor es el número de la carpeta, mayor zoom de la imagen contiene, lo cual genera necesariamente un mayor número de subcarpetas y un mayor número de tiles o teselas de menor tamaño (figura 9). Las carpetas de un número menor tienen menos teselas de mayor tamaño.

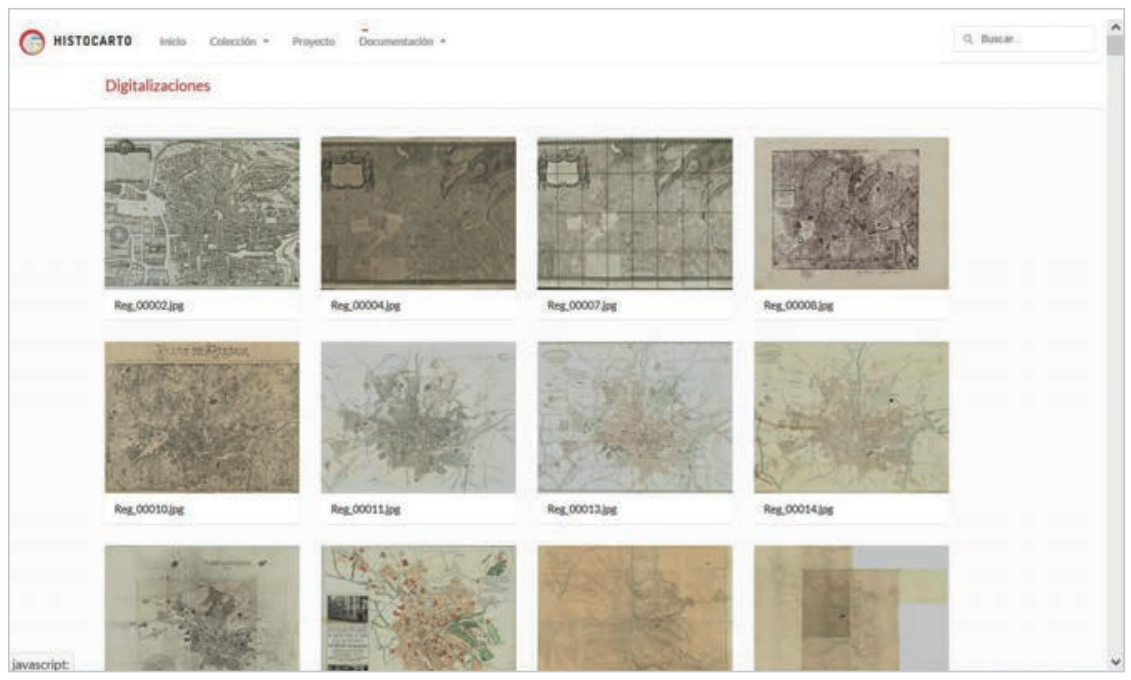

Figura 6. Apartado de digitalizaciones de la web, donde se muestran los registros digitalizados

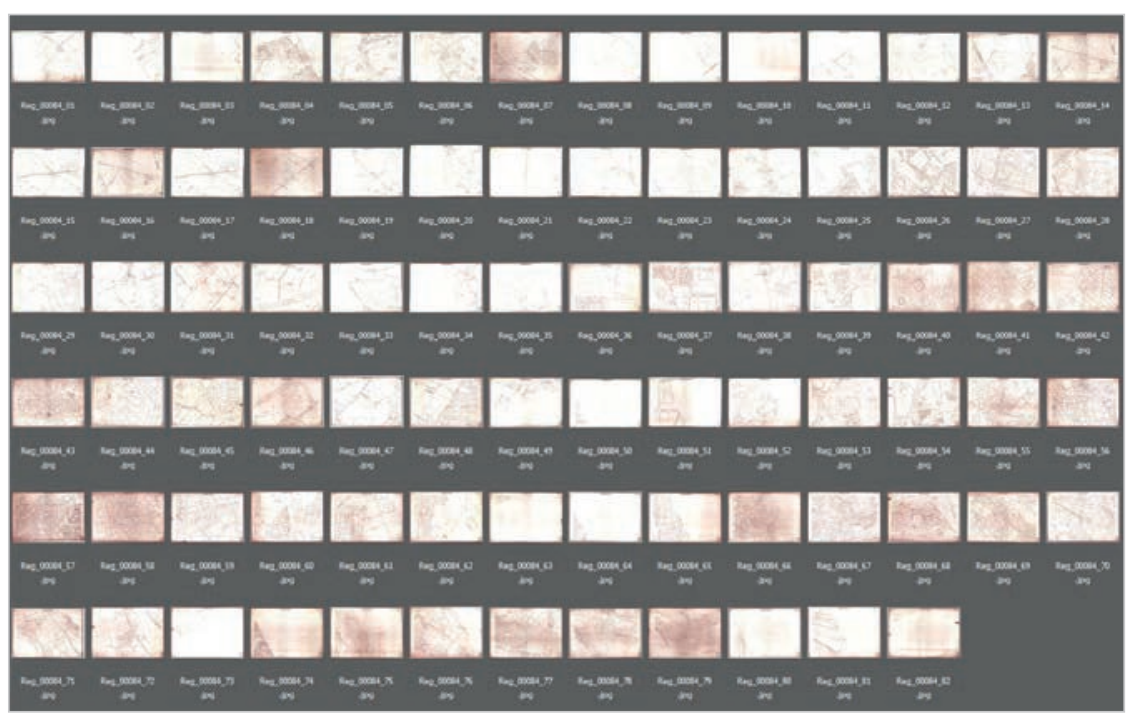

Figura 7. Ejemplo de todos los planos que puede contener un registro compuesto o serie

\begin{tabular}{|c|c|c|c|}
\hline Nombre & Fecha de modifica... & Tipo & Tamaño \\
\hline 120 & $12 / 08 / 201819: 57$ & Carpeta de archivos & \\
\hline a 1 & $12 / 08 / 201819: 57$ & Carpeta de archivos & \\
\hline L 2 & $12 / 08 / 201819: 57$ & Carpeta de archivos & \\
\hline D 3 & $12 / 08 / 201819: 57$ & Carpeta de archivos & \\
\hline 14 & $12 / 08 / 201819: 57$ & Carpeta de archivos & \\
\hline L 5 & $12 / 08 / 201819: 57$ & Carpeta de archivos & \\
\hline 126 & $12 / 08 / 201819: 57$ & Carpeta de archivos & \\
\hline 1) 7 & $12 / 08 / 2018$ 19:57 & Carpeta de archivos & \\
\hline (9) leaflet.html & $12 / 08 / 2018$ 19:35 & Chrome HTML Do... & $3 \mathrm{~KB}$ \\
\hline 27 metadata.json & $12 / 08 / 2018$ 19:35 & Archivo JSON & $3 \mathrm{~KB}$ \\
\hline (C) openlayers.html & $12 / 08 / 201819: 35$ & Chrome HTML Do... & $3 \mathrm{~KB}$ \\
\hline
\end{tabular}

Figura 8. Resultado de la teselación de un plano

3. Cartografía georreferenciada y fotografía geolocalizada. Ambos resultados se observan en toda su dimensión en la web. Aquí mostramos las capturas de pantalla del resultado del proceso de la geolocalización (figuras 10-12). El resultado de la georreferenciación se puede ver en el artículo de MapTiler (Cascón-Katchadourian; Ruiz-Rodríguez, 2016).

La georreferenciación de los planos y la geolocalización de la fotografía permite que estos documentos puedan ser buscados geográficamente por ejemplo a través de Google Maps. 
4. Sitio web. Todos los pasos que acabamos de describir tienen como finalidad principal la creación de un sitio web; se llevan a cabo para poder mostrar y difundir la documentación a través de este medio ideal en nuestros días. Es, por tanto, un resultado que está relacionado con todo lo mostrado hasta ahora y con los apartados siguientes, pero también es un resultado en sí mismo.

La dirección web es un dominio de la Universidad de Granada: histocarto.ugr.es. Ofrece al usuario dos tipos de búsqueda: una textual tradicional y otra geográfica.

La búsqueda textual se divide igualmente en dos: una búsqueda propiamente dicha, que se divide en sencilla y avanzada; y lo que nosotros llamamos browsing o navegación. La búsqueda sencilla es una caja de texto donde se ponen las palabras clave, y el motor de búsqueda rastrea coincidencias en todos los campos de la base de datos. La búsqueda avanzada permite acotar por determinados campos de la base de datos y filtrar los resultados por la fecha, institución, autor, etiquetas, etc. Conecta con el apartado obras.

En cambio, la navegación está concebida desde una triple vertiente: obras, autores e instituciones. Esas tres opciones dependen jerárquicamente de la pestaña "Colección" del sitio web:

- la opción "Obras" (figura 13) consiste en que el geoportal muestra todos los resultados que contiene, tanto de planos como de fotografías. Los resultados se presentan con una imagen de baja resolución, el título, el autor, la institución que la custodia y la fecha. Si se pincha en la imagen vemos el registro completo. Sobre ese listado de resultados se puede activar el filtrado por institución que custodia la documentación; por categoría (plano o fotografía); y por una serie de etiquetas que pueden ser geográficas, urbanísticas, sobre edificios, de materia, fecha, etc. De esta forma el geoportal da respuestas a preguntas como cuántas fotografías hay sobre torres en Granada, cuántos planos del siglo XIX custodia el AHMG. Y así, un largo etc.

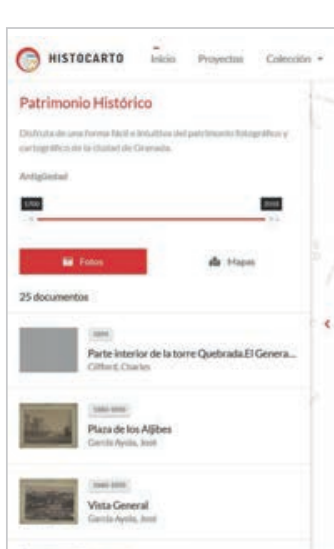

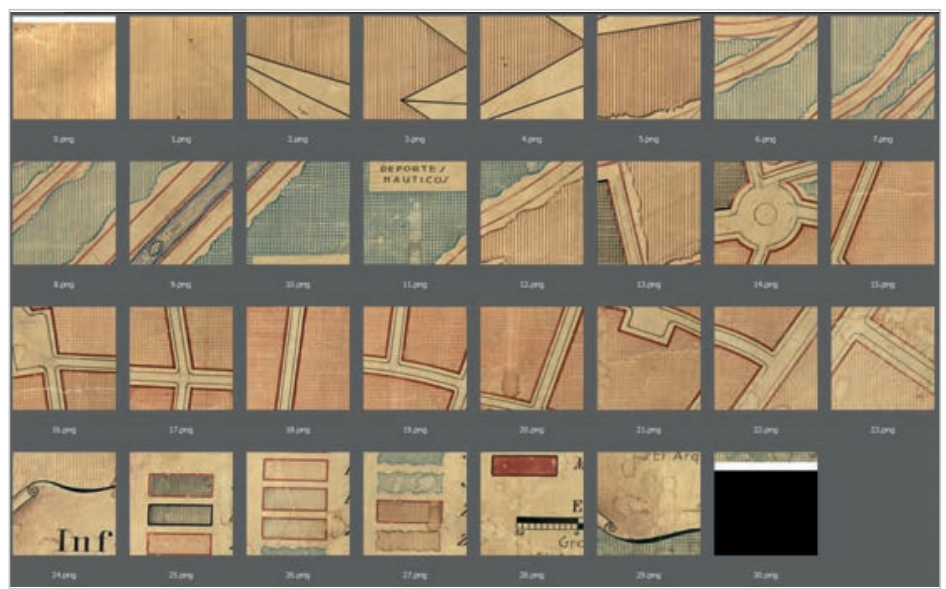

Figura 9. Teselación o división de la imagen en cientos de pequeños trozos

Figura 10. Ejemplo de como se distribuyen en el mapa de la web las fotografías geolocalizadas. Cuando hay varias fotos en la misma zona se agrupan en un número

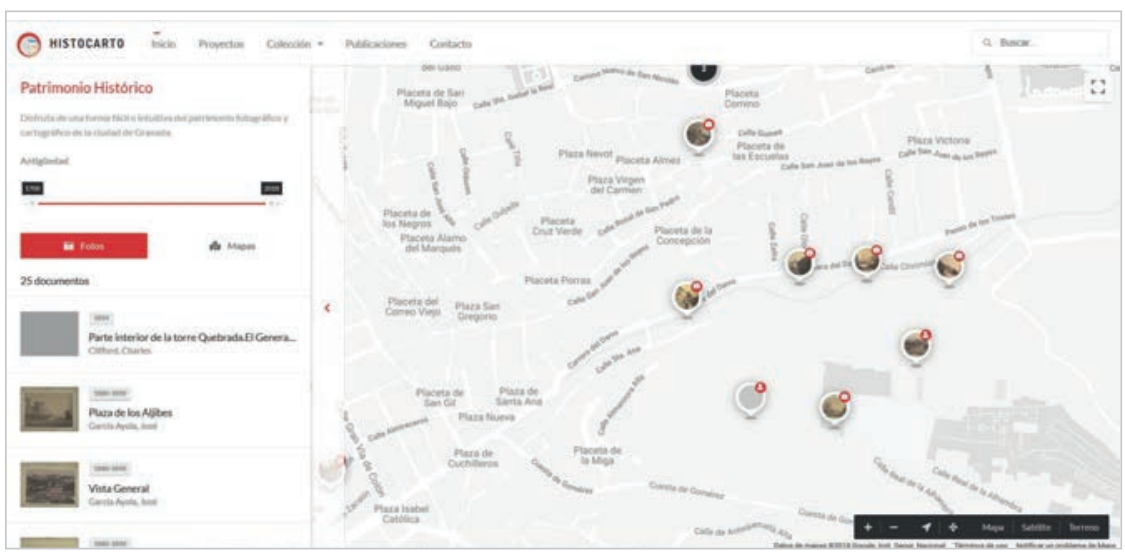

Figura 11. Al acercar el zoom, el agrupamiento en un número desaparece mostrando cada fotografía en su respectivo lugar exacto

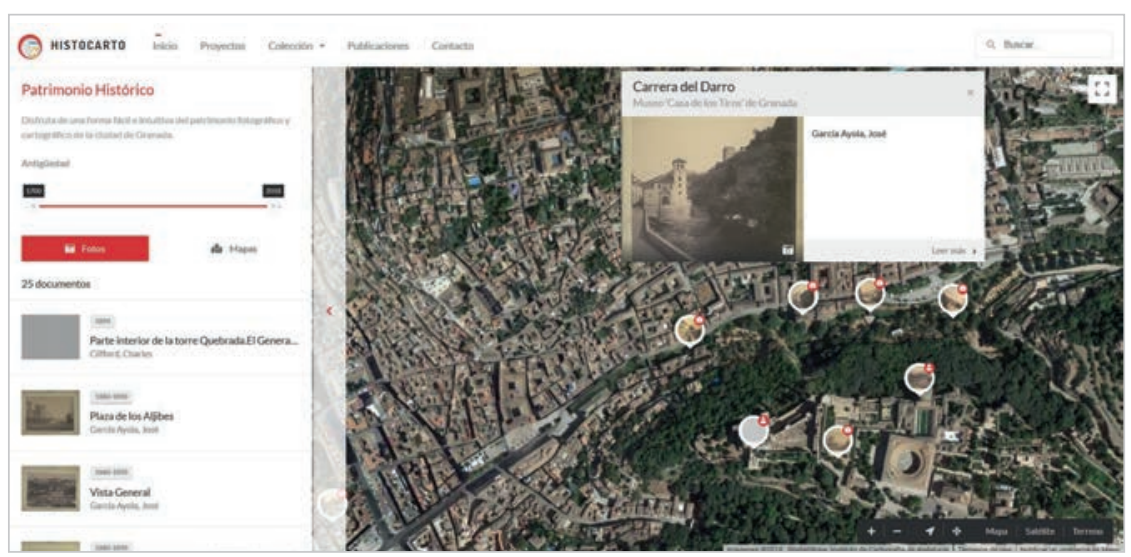

Figura 12. Al pinchar en el icono de la foto geolocalizada se despliega una cartela informativa con los datos más importantes. El mapa también tiene disponible la vista por satélite. 
- la segunda opción nos presenta todos los autores, tanto de fotografías como de cartografía, ordenados alfabéticamente por apellido (Figura 14). Pinchando en cualquiera de ellos aparecen todas las obras creadas por dicho autor. Esto permite responder a preguntas del usuario como cuántas fotografías del autor Jean Laurent tiene el geoportal.

- la tercera opción ofrece todas las instituciones de las cuales se dispone de documentos, de nuevo en orden alfabético. Pinchando en la institución, el geoportal muestra los documentos que posee de esa institución. Posteriormente se puede filtrar por categoría. De esta manera, el usuario tiene la posibilidad de encontrar, por ejemplo, todas las fotografías históricas que tiene nuestro geoportal del AHMG.

En cuanto a la búsqueda geográfica, al haber sido dotados los documentos de coordenadas geográficas y gracias a la programación informática del motor de búsque$d a$, estos pueden ser encontrados navegando por el mapa actual. Además, en el panel de la izquierda hay un filtro de tiempo con su barra temporal correspondiente; también se puede filtrar por tipo de documento (figura 12).

Asimismo, el mapa de la búsqueda geográfica y el panel de la izquierda están conectados, de tal forma que el panel sólo muestra los documentos que están en el ámbito geográfico que está mostrando el mapa de la búsqueda geográfica. También, en el caso de la cartografía, una vez que escogemos un resultado del panel y pinchando en el enlace "superponer como capa en el mapa", éste se despliega en el mapa de la búsqueda geográfica para ver su situación exacta (figura 15) y poder compararlo más rápida y fácilmente.

Una vez el usuario ha encontrado el documento que estaba buscando, la web podrá mostrar la descripción del mismo de una forma atractiva a pantalla completa, con un thumbnail del documento digitalizado de mayor tamaño (figura 16). Esta ficha es interactiva, ofreciendo diversos enlaces a funciones de la web:

- Los campos autor, institución propietaria y etiquetas muestran los otros documentos que tiene el geoportal de dicho autor, dicha institución propietaria o dichas etiquetas respectivamente (figura 17). También está el enlace al recurso original.

- En la descripción y la bibliografía hay enlaces a webs para profundizar en algún aspecto de la descripción del documento.

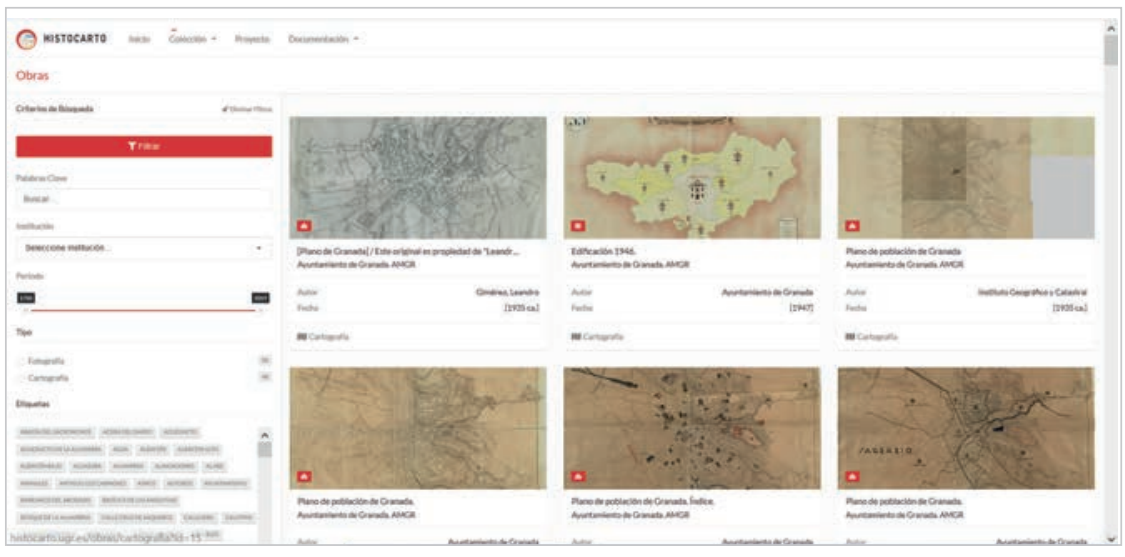

Figura 13. Apartado "Obras"

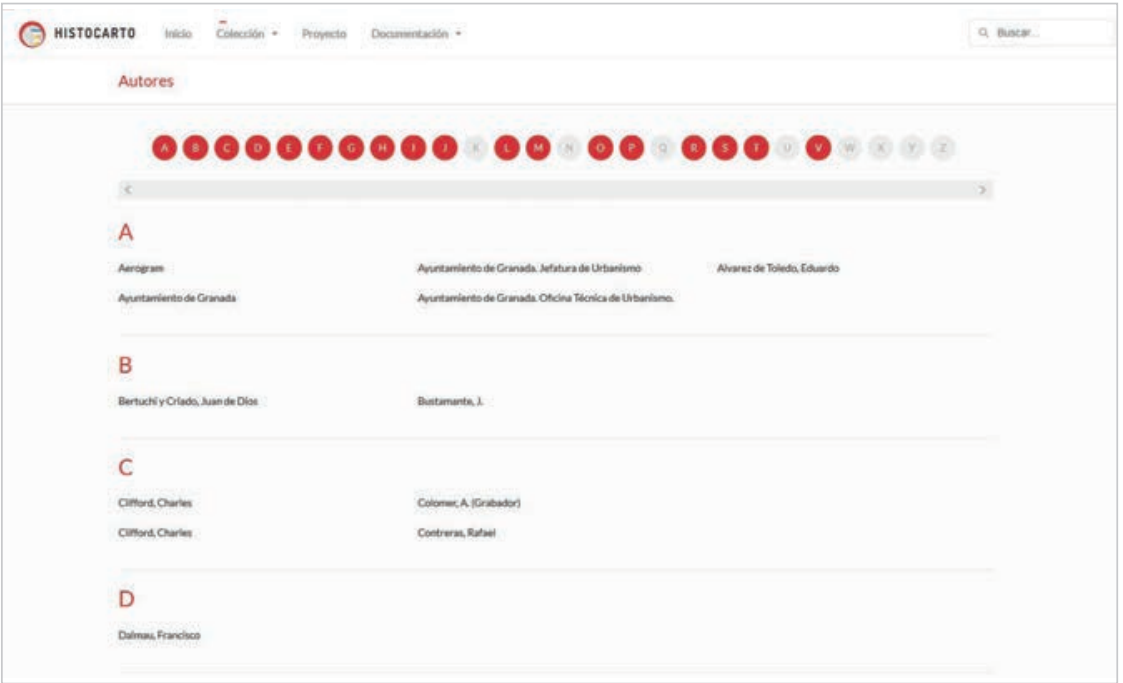

Figura 14. Autores ordenados alfabéticamente

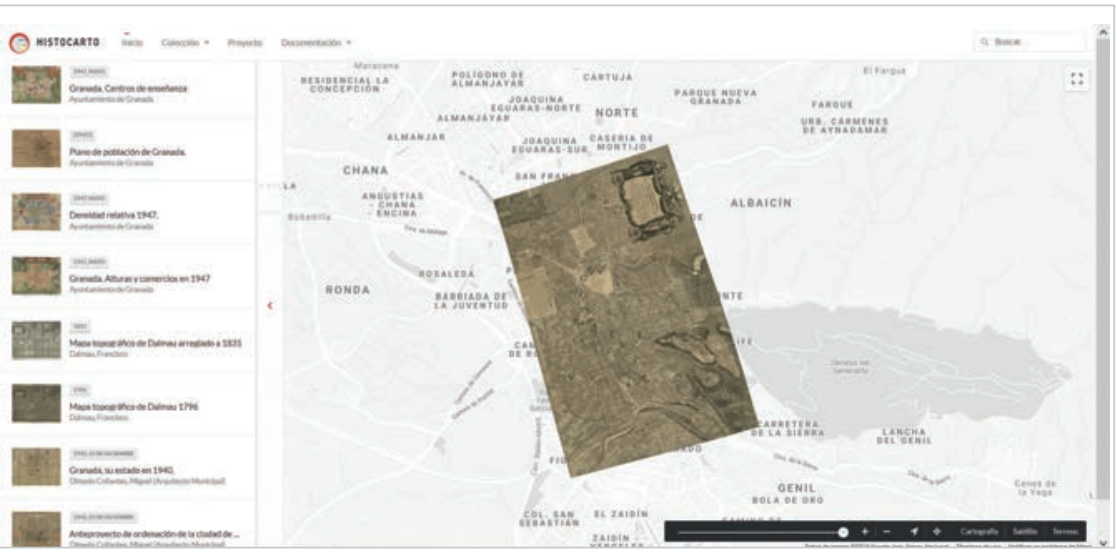

Figura 15. Plano desplegado en la home 
- Existe un botón para ver a tamaño completo y con gran calidad, tanto las fotografías como los planos, gracias a la teselación. En la cartografía se muestra el plano georreferenciado justo debajo con el sensor de transparencia. En la fotografía hay un enlace a la comparación pasado/presente.

5. Comparación pasado/presente. Para la cartografía el resultado es su georreferenciación, su incrustación en un mapa moderno tipo Google Maps y el sensor de transparencia que permite la comparación. Para la fotografía, el resultado es la serie de refotografías que se han realizado en la actualidad.

Una vez seleccionado un resultado, bien a través de la búsqueda textual o bien de la geográfica, y pinchando en la opción de registro completo, encontramos un botón de comparación pasado y presente. Si el resultado es una fotografía, se verá en paralelo la fotografía antigua y la moderna (figura 18). Si el resultado es una cartografía, se verá a tamaño completo el mapa antiguo incrustado sobre el moderno de Google Maps, con el sensor de transparencia para poder comparar los documentos (figura 19).

\section{Conclusiones}

Todas y cada una de las imágenes de la ciudad de Granada son hijas de su tiempo, están influenciadas por la sociedad que las vio nacer, como no puede ser de otra manera. El proyecto Histocarto, igualmente, está influenciado por los tiempos actuales, un tiempo donde el derecho a la información, la necesidad cultural, internet, la digitalización y técnicas como la georreferenciación y la geolocalización se unen para hacer la documentación más accesible a los usuarios. Desde esta investigación pensamos que lo que interesa a los usuarios, más que la institución donde se encuentra la documentación o la norma utilizada para describir la imagen, es la imagen y su poder visual, conocer el lugar donde se tomó una fotografía, poder comparar el documento con la actualidad para observar los cambios acaecidos y enriquecer las descripciones con enlaces a otros documentos.

Por desgracia, esta no es la tónica general en las webs de las instituciones que muestran documentación gráfica: no suelen ofrecer búsquedas geográficas, no se puede comparar el pasado con el presente, en las listas de resultados no se ven imágenes a baja resolución para facilitar la búsqueda al usuario, etc.

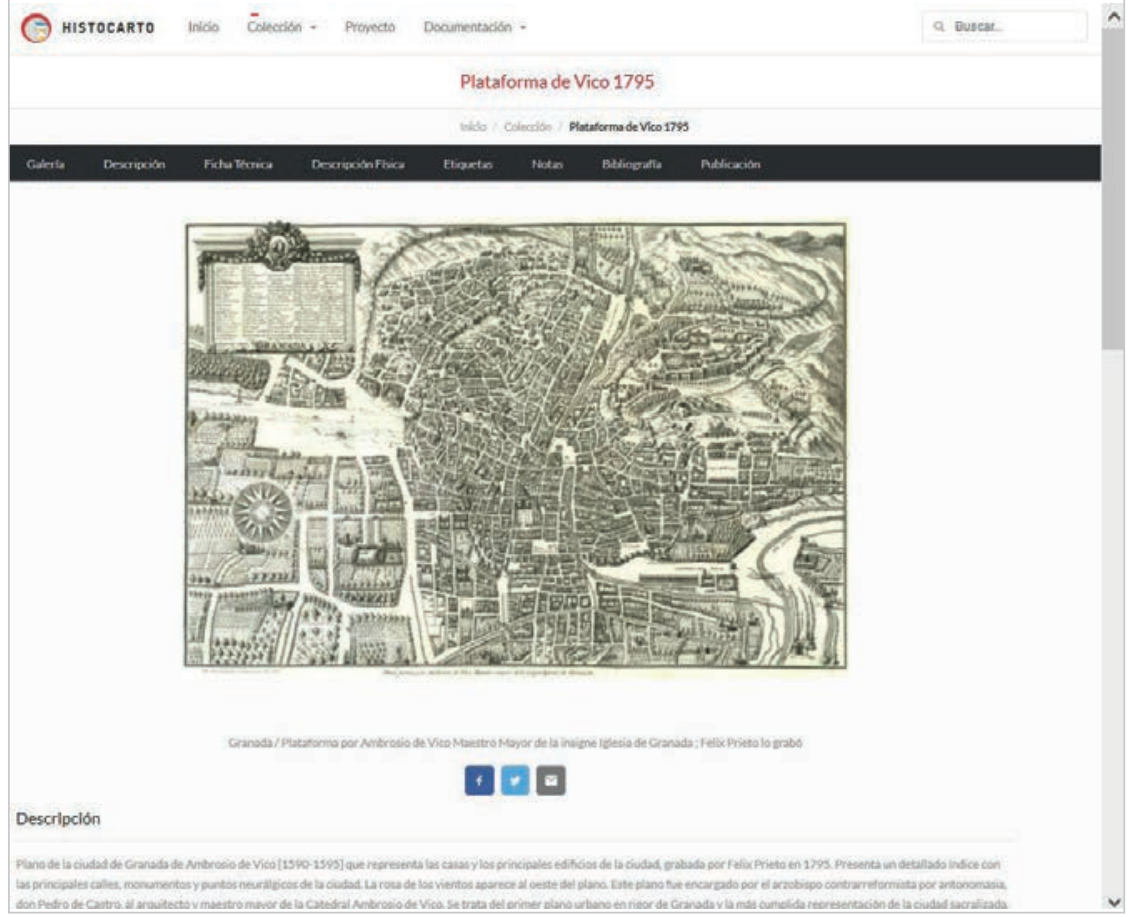

Figura 16. Registro completo. Thumbnail y descripción.

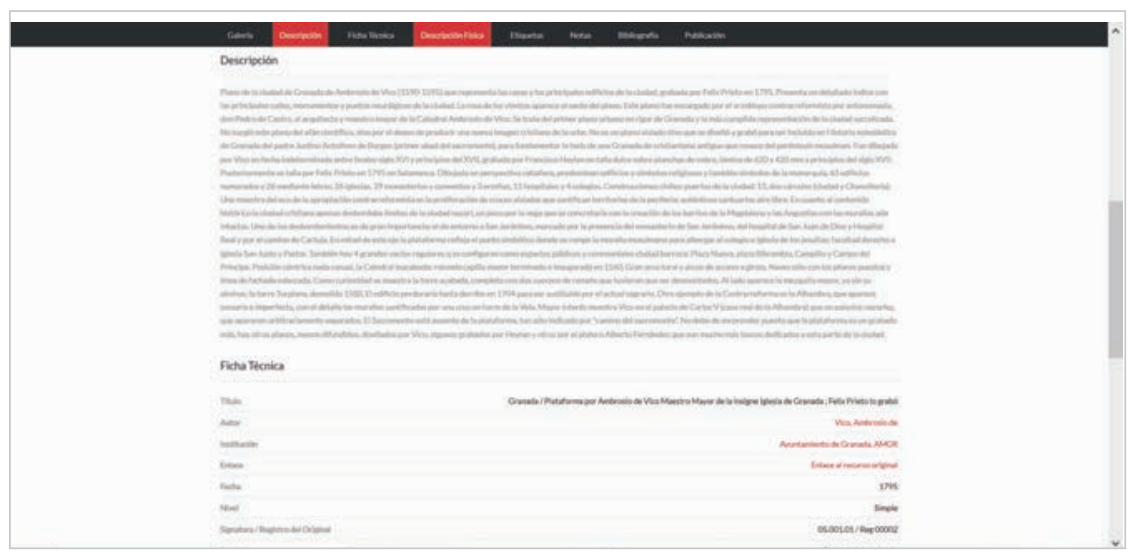

Figura 17. Registro completo. Detalle de enlaces interactivos.

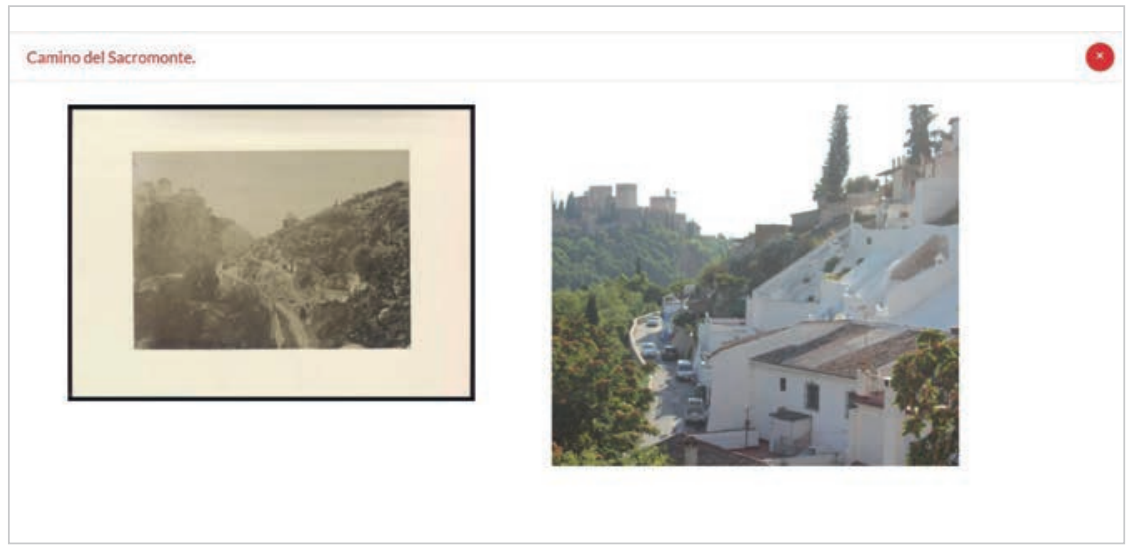

Figura 18. Vista en paralelo de la fotografía antigua y moderna en la web 
Tras habernos cerciorado en la tesis doctoral que da origen a este geoportal que la sociedad en general y los investigadores en particular tienen un gran interés por este tipo de documentación, y que ello no era correspondido con portales web por parte de las instituciones públicas que facilitaran al usuario la adquisición de conocimiento, nos decidimos a hacer esta investigación que creemos plenamente justificada.

Para ello, nos planteamos un objetivo fundamental que era mejo-

rar la recuperación de la información de las imágenes gráficas y, por tanto, darlas a conocer. Entendemos que dicho objetivo con la web Histocarto ha sido razonablemente satisfecho. Para poder satisfacer ese objetivo principal hemos ido cumpliendo con los objetivos específicos marcados; todos se han llevado a cabo con éxito.

La web permite la búsqueda geográfica y su diseño permite la creación de relaciones y enlaces entre los documentos.

Nuestra web permite relacionar unos documentos con otros que estén etiquetados con las mismas palabras clave, con el mismo autor o institución de origen, o con documentos próximos geográficamente, al igual que, un usuario de una biblioteca, gracias a la CDU, puede ver los libros relacionados a uno determinado por estar en el mismo pasillo y estante.

Por otro lado, una fotografía perfectamente descrita por una persona experta en la materia podría conseguir que fuera encontrada con más facilidad a través de un buscador textual. Por desgracia, en la mayoría de las fotografías y planos la descripción que poseen es más administrativa que descriptiva. Aunque estuviera perfectamente descrita, es más intuitiva la búsqueda geográfica.

Nuestro sitio web conjuga todas estas cosas:

- una búsqueda geográfica de la documentación más intuitiva;

- establecimiento de relaciones entre los documentos con objeto de facilitar el encuentro de otros documentos pertinentes;

- a todo ello se le añade una búsqueda avanzada textual con filtros por tipo de documento, etiquetas, institución, autor, etc.

En el trascurso de esta investigación nos hemos ido dando cuenta de una serie de déficits en este campo. Por ello, queremos mostrar en estas conclusiones cuáles son esos déficits y qué soluciones posibles podrían encontrarse, a modo de trabajos o líneas de investigación futuras.

1. En la tesis doctoral que da origen a esta investigación se realizó un catálogo de la cartografía histórica de la ciudad de Granada (ya que la misma es abarcable), que se encuentra colgado en la web en la pestaña documentación, subapartado publicaciones con el nombre de Catálogo general de cartografía histórica. Una posible línea de investigación sería la realización de un catálogo de las fotografías históricas del siglo XIX, sobre la ciudad de Granada y de temática urbanística, que estén tanto en manos públicas como privadas. Es un trabajo ingente que daría para una tesis doctoral.

2. Otro déficit lo constituye el hecho de que no se han encontrado normas, recomendaciones, directrices o guías que se refieran exclusivamente a la digitalización de cartografía o fotografía histórica. Para este punto de la investigación podemos tomar como referencia las Directrices para proyectos de digitalización de colecciones y fondos de dominio público, en particular para aquellos custodiados en bibliotecas y archivos (IFLA; ICA, 2014), en concreto su apéndice de bibliografía donde aparecen 19 normativas generales y unas 80 referencias acerca de temas especializados; ninguna de ellas se refiere exclusivamente a los materiales con los que nuestra investigación trabaja. De hecho, el apéndice A a la traducción española de dicha publicación, cuyo título es Borrador de pliego de prescripciones técnicas para la digitalización de colecciones de patrimonio bibliográfico, comienza de la siguiente manera "La digitalización de los documentos impresos y manuscritos, así como la del resto de materiales especiales (fotografías, postales, carteles, planos, grabados, mapas, música impresa, etc.)". Todo este material sólo merece la denominación de "materiales especiales".

Dado que la cartografía histórica suele tener grandes dimensiones y está realizada en muy diferentes materiales, y dado que la fotografía histórica esta realizada
El proyecto Histocarto está influenciado por los tiempos actuales, un tiempo donde el derecho a la información, la necesidad cultural, internet, la digitalización y técnicas como la georreferenciación y la geolocalización se unen para hacer la documentación más accesible a los usuarios 
en multitud de soportes (papel, plástico, vidrio, metal, etc.), y que para formar la imagen se usan diversas sustancias fotosensibles: placas metálicas, amalgama de mercurio y plata, pigmentos, tintes, platino, sales de hierro, etc. (Del-Valle-Gastaminza, 1999), creemos necesaria una normativa específica y un trato diferente a la hora de digitalizarse y tratarse.

3. En cuanto a la normativa de descripción de cartografía, comprobamos que existe la normativa ISBD (CM) para cartografía en una biblioteca, no así una específica de la ISAD para cartografía en archivos, a pesar de haberse demostrado que estas normativas son insuficientes para una descripción profesional de la cartografía manuscrita (García-Ruipérez, 2010). Por ello, proponemos como línea de investigación futura la realización de una normativa de descripción de la cartografía, parecida a lo que luego veremos que es Sepiades para la fotografía, teniendo más en cuenta, eso sí, la opinión de los archiveros, ya que son los archivos las instituciones que mayoritariamente guardan este tipo de documentación (Líter-Mayayo, 2012). Además, habría que separar la información administrativa de la descriptiva, que es la que realmente interesa al usuario.

4. La documentación fotográfica sí tiene una norma de catalogación específica, se trata de Sepiades (Sepia Data Element Set) (ICA, 2019), unas recomendaciones para catalogar colecciones fotográficas auspiciadas por la European Commission on Preservation and Access, surgidas a raíz del proyecto Sepia (Safeguarding European Photographic Images for Access). Para museos y bibliotecas es el único modelo de datos creado para describir fondos y colecciones fotográficas (Sánchez-Vigil; Salvador-Benítez, 2013). Como muchas otras normas, surge para hacer interoperables los catálogos, ya que tanto la digitalización como la subida de documentos a la red empezaba a ser frecuente. Se desarrolló entre 1999 y 2003 y es una interesante referencia en el sector (Salvador-Benítez, 2015).

En nuestro proyecto no la hemos usado por varios motivos:

- no están adaptadas para colecciones como la nuestra, que provienen de distintas instituciones, están orientadas para describir una colección institucional;

- normaliza campos como la posición geográfica que a nosotros no nos sirven pues esto lo describimos con coordenadas geográficas;

- carece de importantes conceptos en el ámbito de los archivos, lo que provoca dificultades a la hora de conseguir interoperabilidad con el modelo ISAD (G) (Sánchez-Vigil; Salvador-Benítez, 2013).

Todos estos déficits de la norma son los que hacen que pensemos que una futura línea de investigación sería mejorar todos estos aspectos para que sea útil para proyectos como el nuestro.

5. Además, más que una futura línea de investigación, un trabajo que se debería realizar es georreferenciar la cartografía y geolocalizar la fotografía histórica de las instituciones, que en vez de ser proyectos puntuales pasen a ser masivos.

6. Por último, desde esta investigación pensamos que un gran número de usuarios querría buscar por el nombre de una calle, plaza, monumento, en definitiva, por cualquiera de las etiquetas, direcciones, topónimos, etc., que pueden aparecer en un plano o mapa. Desde esta perspectiva sería una tarea bastante útil, aunque laboriosa, describir el contenido de esas etiquetas manualmente e introducirlas en la base de datos. Esta labor raramente se hace debido a la falta de tiempo.

Como futura línea de investigación sería interesante la creación de un software OCR (optical character recognition) que sea capaz de capturar el texto de los rótulos de los mapas, ya que los actuales no son capaces de hacerlo al estar en distintas orientaciones o tamaños. Otra posibilidad para llegar a un fin parecido sería obtener el nombre de las calles a través de un SIG de forma automática; una vez que el plano está georreferenciado, sacar el nombre de esas calles de una forma semiautomática.

\section{Notas}

1. Este trabajo está basado en la tesis doctoral de Jesús Cascón-Katchadourian (Cascón-Katchadourian, 2018).

2. Existen otras definiciones. Queremos destacar aquí la del artículo 49.1 de la Ley 16/1985, de 25 de junio, del Patrimonio Histórico Español (España, 1985).

\section{Referencias}

Acuña-Piedra, Jessica-Francini; Quesada-Román, Adolfo (2016). “Evolución geomorfológica entre 1948 y 2012 del delta Térraba-Sierpe, Costa Rica”. Cuaternario y geomorfología, v. 30, n. 3-4, pp. 9-28. https://doi.org/10.17735/cyg.v30i3-4.53055

Adobe (2018). "Creación y edición de imágenes panorámicas. Creación de imágenes panorámicas Photomerge”. Adobe. https://helpx.adobe.com/es/photoshop/using/create-panoramic-images-photomerge.html

ArcGIS (2013). “¿Qué son los datos ráster?”. ArcMap.

https://desktop.arcgis.com/es/arcmap/10.3/manage-data/raster-and-images/what-is-raster-data.htm 
ArcGIS (2016). "Principios básicos de georreferenciación de un dataset ráster". ArcMap.

http://desktop.arcgis.com/es/arcmap/10.3/manage-data/raster-and-images/fundamentals-for-georeferencing-a-rasterdataset.htm

Armstrong, Natasha (2012). "Historypin: Bringing generations together around a communal history of time and place". Journal of intergenerational relationships, v. 10, n. 3, pp. 294-298.

https://doi.org/10.1080/15350770.2012.697412

Ayuntamiento de Barcelona (2018). “BCN Visual, una app para conocer la Barcelona desaparecida”. L'Eixample, 2 agosto. https://ajuntament.barcelona.cat/eixample/es/noticia/bcn-visual-una-app-para-conocer-la-barcelona-desaparecida_695414

Ayuntamiento de Barcelona (2019). Els "Quarterons Garriga i Roca". Barcelona, darrera mirada. Arxiu Històric de la Ciutat de Barcelona.

http://darreramirada.ajuntament.barcelona.cat/\#

Baggett, Mark; Gibbs, Rabia (2014). "Historypin and Pinterest for digital collections: Measuring the impact of image-based social tools on discovery and access". Journal of library administration, v. 54, n. 1, pp. 11-22.

https://doi.org/10.1080/01930826.2014.893111

Beltrán-López, Gersón (2015). “La geolocalización social”. Polígonos. Revista de geografía, n. 27. https://doi.org/10.18002/pol.v0i27.3290

Cascón-Katchadourian, Jesús-Daniel (2018). Documentación histórica gráfica granadina. Aplicación de herramientas SIG para mejorar su recuperación: georreferenciación y geolocalización. Tesis doctoral. Granada: Universidad de Granada. ISBN: 9788413060385

http://digibug.ugr.es/handle/10481/54300

Cascón-Katchadourian, Jesús-Daniel; Ruiz-Rodríguez, Antonio-Ángel. (2016). “Descripción y valoración del software MapTiler: del mapa escaneado a la capa interactiva publicada en la Web". El profesional de la información, v. 25, n. 6, pp. $970-978$.

https://doi.org/10.3145/epi.2016.nov.13

Cascón-Katchadourian, Jesús-Daniel; Ruiz-Rodríguez, Antonio-Ángel; Alberich-Pascual, Jordi (2018). "Uses and applications of georeferencing and geolocation in old cartographic and photographic document management". El profesional de la información, v. 27, n. 1, pp. 202-212.

https://doi.org/10.3145/epi.2018.ene.19

Cascón-Katchadourian, Jesús-Daniel; Ruiz-Rodríguez, Antonio-Ángel; Herrera-Viedma, Enrique (2019). “Definición, legislación y normativa para el tratamiento de los documentos históricos generados en la Administración Pública española y andaluza". Revista española de documentación científica, In press.

Cascón-Katchadourian, Jesús-Daniel; Ruiz-Rodríguez, Antonio-Ángel; Quesada-Román, Adolfo (2018). “Georreferenciación y publicación web de cartografía antigua en sistemas de información geográficos: requisitos para su evaluación y estudio de caso". Revista general de información y documentación, v. 28, n. 1.

https://doi.org/10.5209/RGID.60810

Cruz-Mundet, José-Ramón (2001). Manual de archivística. Madrid: Fundación Germán Sánchez Ruipérez. ISBN: 97884 89384316

CSIC (2019). HISDI-MAD. IDE histórica de la ciudad de Madrid. Consejo Superior de Investigaciones Científicas. http://idehistoricamadrid.org/hisdimad/index.htm

Dávila-Martínez, Francisco-Javier; Camacho-Arranz, Elena (2012). “Georreferenciación de documentos cartográficos para la gestión de archivos y cartotecas: 'propuesta metodológica'”. Revista catalana de geografía, v. 17, n. 46. https://repositorio.unican.es/xmlui/handle/10902/1003

Del-Bosque-González, Isabel; Fernández-Freire, Carlos; Martín-Forero-Morente, Lourdes; Pérez-Asensio, Esther (2012). Los sistemas de información geográfica y la investigación en ciencias humanas y sociales. Madrid: Confederación Española de Estudios Locales. ISBN: 9788461598250

https://cutt.ly/2wrxB4K

Del-Valle-Gastaminza, Félix (1999). Manual de documentación fotográfica. Madrid: Editorial Síntesis. ISBN: 97884 77386896

Duplá-Del-Moral, Ana (2009). Manual de archivos de oficina para gestores: Comunidad de Madrid. Madrid: Marcial Pons. ISBN: $847248467 X$

España (1969). “Decreto 914/1969, de 8 de mayo, de creación del Archivo General de la Administración Civil”. BOE, n. 125, 26 mayo, pp. 8093-8093.

https://www.boe.es/buscar/pdf/1969/BOE-A-1969-643-consolidado.pdf 
España (1985). “Ley 16/1985, de 25 de junio, del Patrimonio Histórico Español”. BOE, n. 155, 29 junio, pp. $20342-20352$. https://www.boe.es/buscar/act.php?id=BOE-A-1985-12534

España (1995). Diccionario de terminología archivística. Dirección de Archivos Estatales. ISBN: 847483936X

España (2002). "Real decreto 1164/2002, de 8 de noviembre, por el que se regula la conservación del patrimonio documental con valor histórico, el control de la eliminación de otros documentos de la Administración General del Estado y sus organismos públicos y la conservación de documentos administrativos en soporte distinto al original”. BOE, n. 274, 15 noviembre, pp. 40139-40143.

https://www.boe.es/buscar/doc.php?id=BOE-A-2002-22192

España (2003). Criterios generales para la valoración de los documentos de la Administración General del Estado. (Documento aprobado por la Comisión Superior Calificadora de Documentos Administrativos, en sesión de 27 de noviembre de 2003). Ministerio de Cultura; Comisión Superior Calificadora de Documentos Administrativos.

http://www.culturaydeporte.gob.es/dam/jcr:11a7650b-7490-4ef8-bca2-ead999bbd42e/metodologiacomsup-pdf-Parte1.pdf

España (2011). "Real decreto 1708/2011, de 18 de noviembre, por el que se establece el Sistema Español de Archivos y se regula el Sistema de Archivos de la Administración General del Estado y de sus Organismos Públicos y su régimen de acceso". BOE, n. 284, 25 noviembre, pp. 125573-125592.

https://www.boe.es/buscar/act.php?id=BOE-A-2011-18541

IFLA; ICA (2014). Directrices para proyectos de digitalización de colecciones y fondos de dominio público, en particular para aquellos custodiados en bibliotecas y archivos. Federación Internacional de Asociaciones de Bibliotecarios y Bibliotecas; Consejo Internacional de Archivos; Unesco. http://travesia.mcu.es/portalnb/jspui/handle/10421/3342

Fleet, Christopher; Kowal, Kimberly C.; Přidal, Petr (2012). "Georeferencer: Crowdsourced georeferencing for map library collections". D-Lib magazine, v. 18, n. 11/12.

https://doi.org/10.1045/november2012-fleet

García-Ruipérez, Mariano (2010). “La descripción de documentos cartográficos: estado de la cuestión”. Códices, v. 6, n. 2, pp. 195-208.

http://eprints.rclis.org/20217

Guinchat, Claire; Blanquet, Marie-France; Menou, Michel (1992). Introducción general a las ciencias y técnicas de la información y documentación. Madrid: Cindoc. ISBN: 8400072952

Hapke, Cheryl J.; Reid, David (2007). National assessment of shoreline change part 4: Historical coastal cliff retreat along the California coast. Open File Report 2007-1133. U.S. Department of the Interior; U.S. Geological Survey.

https://cutt.ly/xwueRuK

Harkema, Craig; Nygren, Catherine (2012). "Historypin for library image collections: New modes of access for unique materials at the University of Saskatchewan library". Partnership: The Canadian journal of library and information practice and research, v. 7, n. 2.

https://doi.org/10.21083/partnership.v7i2.1970

Heredia-Herrera, Antonia (1991). Archivística general: teoría y práctica. Sevilla: Excma. Diputación Provincial de Sevilla. ISBN: 847798056X

https://alexavidal.files.wordpress.com/2015/07/archivisticageneralteoriaypractica-antonia-heredia-herrera.pdf

Hill, Linda L. (2009). Georeferencing: the geographic associations of information. MIT Press. ISBN: 9780262512527

ICA (2019). Sepiades. Recommendations for cataloguing photographic collections. International Council on Archives. https://www.ica.org/en/sepiades-recommendations-cataloguing-photographic-collections

Image Access (2019). Book scanner Bookeye ${ }^{\circledR} 3$ R2 - for formats up to DIN A2.

https://www.imageaccess.de/?page=scannersbe3-sgs-r2\&lang=en

Junta de Andalucía (2000). Manual para el funcionamiento interno de los archivos judiciales en Andalucía. Sevilla: Consejería de Justicia y Administración Pública, Dirección General de Relaciones con la Administración de Justicia. https://www.juntadeandalucia.es/export/drupaljda/manual_archivos_judiciales_0.pdf

Junta de Andalucía (2010). Recomendaciones técnicas para la digitalización de documentos. Servicio de Archivos. Dirección General del Libro, Archivos y Bibliotecas. Consejería de Cultura, pp. 1-14.

https://cutt.ly/WwueREf

Klokan Technologies (2019). Klokan Technologies. Maps for people. Online.

https://www.klokantech.com 
Líter-Mayayo, Carmen (2012). Directorio de cartotecas y de colecciones cartográficas en instituciones españolas. Ibercarto. Grupo de Trabajo de Cartotecas Públicas Hispano-Lusas.

http://sge.org/ibercarto/wp-content/uploads/sites/4/2016/12/Directorio_espa\%C3\%B1olas.pdf

Long, Tengfei; Jiao, Weili; He, Guojin; Zhang, Zhaoming (2016). "A fast and reliable matching method for automated georeferencing of remotely-sensed imagery". Remote sensing, v. 8, n. 1.

https://doi.org/10.3390/rs8010056

MapTiler (2019). Features of MapTiler Desktop.

https://www.maptiler.com/desktop

Masó, Joan; Julià, Núria; Pons, Xavier (2008). "Historia y estado actual del futuro estándar Web Map Tiling Service del OGC". In: $5^{\text {th }}$ Spanish SDI meeting.

http://www.creaf.uab.es/Miramon/publicat/papers/jidee08/WebMapTilingService_MasoJuliaPons.pdf

Oehrli, Markus; Přidal, Petr; Zollinger, Sussane; Siber, Robi (2011). “MapRank: Geographical search for cartographic materials in libraries". D-lib magazine, v. 17, n. 9/10.

http://www.dlib.org/dlib/september11/oehrli/09oehrli.html

https://doi.org/10.1045/september2011-oehrli

Ortiz-Caña, Francisco (2016). “Geolocalización vs georreferenciación”. Ubikua. Geolocalización, realidad aumentada y LBS. http://www.ubikua.com/2016/08/geolocalizacion-vs-georreferenciacion.html

Podobnikar, Tomaž (2010). "Historical maps of Ljubljana for GIS applications”. Acta geodaetica et geophysica Hungarica, v. 45, n. 1 , pp. $80-88$.

https://doi.org/10.1556/AGeod.45.2010.1.12

Quesada-Román, Adolfo; Acuña-Piedra, Jéssica-Francini (2017). “Efectos climáticos y antrópicos en la morfogénesis de isla Guarumal, Humedal Nacional Térraba-Sierpe, Costa Rica". Revista de ciencias ambientales, v. 51, n. 2, pp. 169-180. https://www.revistas.una.ac.cr/index.php/ambientales/article/view/9485 https://doi.org/10.15359/rca.51-2.9

Ramos, Noelia; Roset, Rafael (2012). "Georeferenciación de mapas antiguos con la ayuda de usuarios”. Revista catalana de geografía, v. 17, n. 46.

http://www.rcg.cat/articles.php?id=257

Rodríguez-Bravo, Blanca (2002). El documento: entre la tradición y la renovación. Gijón: Ediciones Trea. ISBN: 849704052X Rumsey, David (2019). David Rumsey Map Collection. https://www.davidrumsey.com

Rumsey, David; Punt, Edith M. (2005). Cartographica extraordinaire: The historical map transformed. Esri Press. ISBN: 9781489480445

Rumsey, David; Williams, Meredith (2002). "Historical maps in GIS". In: Knowles, Anne-Kelly. Past time, past place: GIS for history, pp. 1-18. ISBN: 9781589480322

Salvador-Benítez, Antonia (2015). "Conocer y describir el patrimonio fotográfico". En: Salvador-Benitez, Antonia. Patrimonio fotográfico. De la visibilidad a la gestión. Gijón: Editorial Trea, pp. 19-50. ISBN: 9788497048552

San-Antonio-Gómez, Carlos; Velilla, Cristina; Manzano-Agugliaro, Francisco (2014). “Urban and landscape changes through historical maps: The Real Sitio of Aranjuez (1775-2005), a case study". Computers, environment and urban systems, v. 44, pp. 47-58. https://doi.org/10.1016/j.compenvurbsys.2013.12.001

Sánchez-Vigil, Juan-Miguel; Salvador-Benítez, Antonia (2013). Documentación fotográfica. Barcelona: Editorial UOC; col. El profesional de la información, n. 18. ISBN: 8490640440

Schellenberg, Theodore (1961). Técnicas descriptivas de archivos. Córdoba (Argentina): Universidad Nacional de Córdoba.

Southall, Humphrey; Přidal, Petr (2012). “Old maps online: Enabling global access to historical mapping". E-perimetron, v. 7, n. 2, pp. 73-81.

https://researchportal.port.ac.uk/portal/files/158847/Southall_Pridal.pdf

Timeline Trip (2019). Timeline Trip.

http://timelinetrip.com/es

Witmer, Alan; Hagan, James; Scaffidi, Brian; Hancock, Jon (2006). "Automated georeferencing of digitized map images". Google Patents.

https://patents.google.com/patent/US20060041375 